\title{
Isolated Homocysteinemia Leading to Thromboembolism in Young Male with Normal Vitamin B12 and Folate Levels
}

Waleed Sadiq $^{1}$, Madeeha Subhan ${ }^{2}$

1. Internal Medicine, Shifa International Hospital, Islamabad, PAK 2. Capital Hospital Islamabad, Ayub Teaching Hospital, Abbottabad, Islamabad, PAK

$\square$ Corresponding author: Waleed Sadiq, waleedsadiq01@gmail.com

Disclosures can be found in Additional Information at the end of the article

\section{Abstract}

Pulmonary embolism (PE) with isolated homocysteinemia is a rare disease. The diagnosis demands a proper clinical workup. Timely diagnosis can prevent complications and provide a better quality of life for the patient. We present a young man with homocysteinemia with deep vein thrombosis (DVT), pulmonary embolism, and normal vitamin B12 and folate levels despite being treated with rivaroxaban.

Categories: Genetics, Internal Medicine, Pulmonology

Keywords: dvt, pulmonary embolism, hyperhomocysteinemia, thrombophilia

\section{Introduction}

An elevated level of homocysteine in the body is known as homocysteinemia or hyperhomocysteinemia. The normal blood levels of homocysteine range from 5-15 $\mu \mathrm{mol} / \mathrm{L}$ [12]. Individuals with severe hyperhomocysteinemia have homocysteine concentrations in the range of 50 to $500 \mathrm{ftmol} / \mathrm{L}$ [3]. An elevated level of homocysteine is a risk factor for arterial and venous thromboembolism [4]. There is a consistent relationship between plasma homocysteine levels and atherosclerotic vascular disease [5]. We present a nonsmoker, nonalcoholic young man diagnosed with homocysteinemia with deep vein thrombosis (DVT), pulmonary embolism (PE), and right ventricle (RV) dilation with normal vitamin B12 and folate levels.

\section{Case Presentation}

A 34-year-old, married, previously healthy man presented to our hospital outpatient department on December 7, 2017, with pain, tenderness, and swelling in his left leg for one

Received 08/07/2017

Review began 12/18/2017 Review ended 12/18/2017 Published 12/22/2017

(c) Copyright 2017

Sadiq et al. This is an open access article distributed under the terms of the Creative Commons Attribution License CC-BY 3.0., which permits unrestricted use, distribution, and reproduction in any medium, provided the original author and source are credited. week. The pain was sudden in onset and sharp, movement made the pain worse, and rest relieved it. The pain was localized to the lower leg and did not radiate. In addition to pain, he had a tense swelling of the lower extremity. No temperature changes were associated. This was his first episode. The patient was admitted and appropriately evaluated for DVT, including Doppler ultrasound and blood work. He was started on anticoagulation therapy with oral rivaroxaban. The patient tolerated the treatment well, and his prothrombin time and activated partial thromboplastin time were monitored. Five days after admission and receiving an anticoagulant, he developed dyspnea and hyperventilation in the morning. His arterial blood gas test showed respiratory alkalosis. Because the probability of PE was high, he was given a heparin infusion and was taken for a pulmonary angiogram, which showed a thrombus in the right pulmonary artery, involving the right upper middle and lower lobar arteries. Since sudden onset DVT and subsequent PE in a young male patient, despite being on anticoagulation, is 


\section{Cureus}

rare, it raised a suspicion of underlying thrombophilia. A panel was ordered that came back positive for high levels of homocysteine. After the patient stabilized, he was again prescribed oral rivaroxaban. Vitamin B12, folate, and vitamin B6 levels were evaluated and found to be surprisingly normal because homocysteinemia is usually associated with vitamin B12 deficiency. He was also started on vitamin B6, vitamin B12, and folate.

\section{Physical exam}

The measurements of his legs before and after anticoagulation therapy are presented in Table 1 .

Left leg (cm)

Examination on presentation

Knee

34

37

24

Ankle

Examination after anticoagulation

Knee

34

34

Ankle

\section{Right leg (cm)}

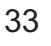

33

24

33

33

24

TABLE 1: Physical exam of both legs before and after treatment

Notable results from the laboratory workup and coagulation profile are presented in Table 2 and Table 3, respectively. His homocysteine level was greater than $65 \mu \mathrm{mol} / \mathrm{L}$. No other findings were remarkable. 


\section{Cureus}

\section{Serum values}

Sodium

$136 \mathrm{mEq} / \mathrm{L}$

Potassium

$4.1 \mathrm{mEq} / \mathrm{L}$

Alanine aminotransferase

$83 \mathrm{U} / \mathrm{L}$

Lipid profile

Triglycerides

$162 \mathrm{mg} / \mathrm{dL}$

Cholesterol

$108 \mathrm{mg} / \mathrm{dL}$

\section{TABLE 2: Laboratory workup including serum electrolytes and lipid profile}

Prothrombin time

Activated partial thromboplastin time
$17 \mathrm{sec}$

$34 \mathrm{sec}$

\section{TABLE 3: Coagulation profile of the patient at the time of presentation}

His dilated RV diameter was $27.9 \mathrm{~mm}$. The Doppler ultrasound revealed thrombotic plaques in the superficial femoral vein at the midthigh level, involving the popliteal, posterior tibial, and peroneal veins. The veins were dilated and noncompressible. His perforator veins were dilated in the calf region. An electrocardiogram showed an S1Q3 pattern. The pulmonary angiogram showed thrombus in the distal right pulmonary artery, as shown in Figure 1. We also noted mild lymph node enlargement, the largest approximately $5 \mathrm{~mm}$ to $9 \mathrm{~mm}$, in the aortopulmonary window. The anticardiolipin antibody test result was negative. D dimers were 1290 ng/mL (i.e., positive). 


\section{Cureus}

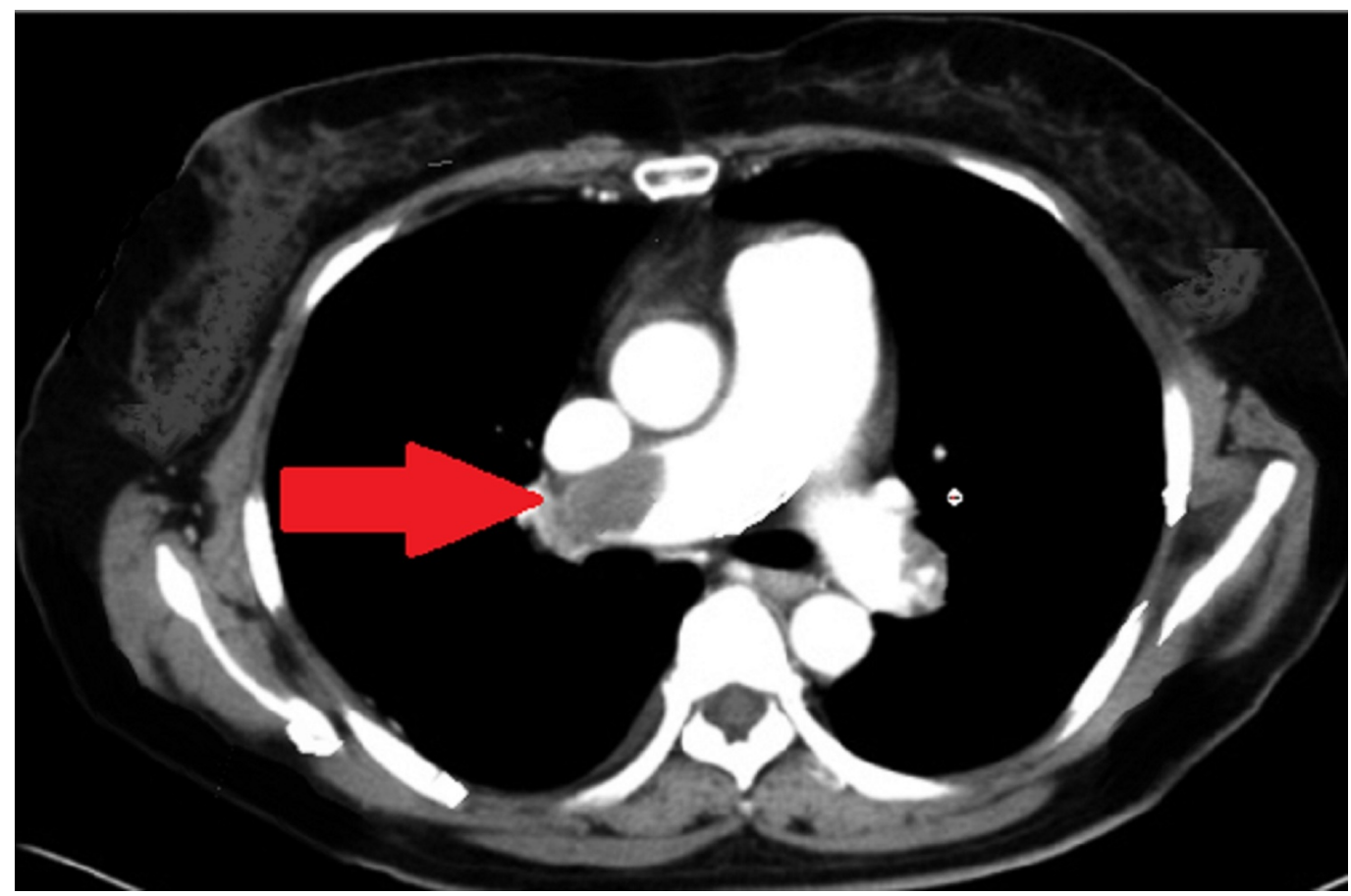

FIGURE 1: CT pulmonary angiogram showing thrombus in the right pulmonary artery

CT: computed tomography

\section{Discussion}

Elevated homocysteine is a strong risk factor for thrombosis and pulmonary embolism [4]. The classification of hyperhomocysteinemia is as follows: (1) moderate risk, 15 to $30 \mu \mathrm{mol} / \mathrm{L}$; (2) intermediate risk, 30 to $100 \mu \mathrm{mol} / \mathrm{L}$; (3) severe risk, >100 $\mathrm{mol} / \mathrm{L}[6]$. Our patient had abnormally high homocysteine levels with normal vitamin B12 and folate levels. The patient's mean corpuscular volume was in the normal range, with no macrocytosis on peripheral film. Despite being on appropriate anticoagulation with rivaroxaban for five days, he developed PE. It is necessary to monitor a patient with homocysteinemia carefully due to the high risk of recurrence of thromboembolic events. Homocysteine is a sulfhydryl amino acid formed by the demethylation of dietary methionine [7]. Homocysteine levels in the blood are usually elevated in patients with folate deficiency because folate is required for the remethylation of homocysteine to methionine. A case-control study by Falcon et al. found that hyperhomocysteinemia was a risk factor for thrombosis in people younger than 40 years [8]. Vitamins B6 and B9 or B12 supplements, while they lower homocysteine level, do not change the risk of heart disease, stroke, or death [9].

\section{Conclusions}

Homocysteinemia is a rare autosomal disease. Any young patient presenting with DVT should have his homocysteine level checked, and despite getting appropriate coagulation, such patient should be carefully monitored for PE, as early recognition of the problem can not only reverse but prevent PE. In some patients, vitamin B12 and folate levels can be normal, with no macrocytic anemia, but isolated homocysteinemia should be a differential diagnosis, as it can cause thromboembolism. 


\section{Additional Information \\ Disclosures}

Human subjects: Consent was obtained by all participants in this study. Conflicts of interest: In compliance with the ICMJE uniform disclosure form, all authors declare the following:

Payment/services info: All authors have declared that no financial support was received from any organization for the submitted work. Financial relationships: All authors have declared that they have no financial relationships at present or within the previous three years with any organizations that might have an interest in the submitted work. Other relationships: All authors have declared that there are no other relationships or activities that could appear to have influenced the submitted work.

\section{References}

1. Ueland PM, Refsum H, Stabler SP, Malinow MR, Andersson A, Allen RH: Total homocysteine in plasma or serum: methods and clinical applications. Clin Chem. 1993, 39:1764-1779.

2. Weiss N, Keller C, Hoffmann U, Loscalzo J: Endothelial dysfunction and atherothrombosis in mild hyperhomocysteinemia. Vasc Med. 2003, 7:227-239. 10.1191/1358863x02vm428ra

3. Mansoor MA, Ueland PM, Aarsland A, Svardal AM: Redox status and protein binding of plasma homocysteine and other aminothiols in patients with homocystinuria. Metabolism. 1993, 42:1481-1485. 10.1016/0026-0495(93)90202-Y

4. Welch G, Loscalzo J: Homocyteine and atherothrombosis. N Engl J Med. 1998, 338:1042-1050. 10.1056/NEJM199804093381507

5. Cattaneo M: Hyperhomocysteinemia, atherosclerosis and thrombosis. Thromb Haemost. 1999, 81:165-176.

6. Hankey GJ, Eikelboom JW: Homocysteine and vascular disease. Lancet. 1999, 354:407-413. 10.1016/S0140-6736(98)11058-9

7. Faeh D, Chiolero A, Paccaud F: Homocysteine as a risk factor for cardiovascular disease: should we (still) worry about it?. Swiss Med Wkly. 2006, 136:745-756.

8. Falcon CR, Cattaneo M, Panzeri D, Martinelli I, Mannucci PM: High prevalence of hyperhomocyst(e)inemia in patients with juvenile venous thrombosis. Arterioscler Thromb. 1994, 14:1080-1083. 10.1161/01.ATV.14.7.1080

9. Martí-Carvajal AJ, Solà I, Lathyris D: Homocysteine-lowering interventions for preventing cardiovascular events. Cochrane Database Syst Rev. 2015, 10.1002/14651858.CD006612.pub5 